EFOMP Policy Statement

\title{
The European Federation of Organisations for Medical Physics Policy Statement No. 6.1: Recommended Guidelines on National Registration Schemes for Medical Physicists
}

\author{
Stelios Christofides a,*, Jorge Isidoro ${ }^{b}$, Csilla Pesznyak ${ }^{c}$, Lada Bumbure ${ }^{d}$, Florian Cremers ${ }^{e}$, \\ Werner F.O. Schmidt ${ }^{\mathrm{f}}$ \\ ${ }^{a}$ Biomedical Research Foundation, P.O. Box 24039, Nicosia 1700, Cyprus \\ b Coimbra Hospital and University Centre, Praceta Prof Mota Pinto, Coimbra 3000-075, Portugal

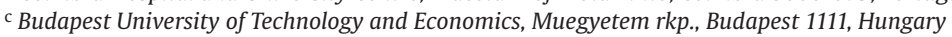 \\ d Riga Technical University, Kalku street 1, Riga LV-1658, Latvia \\ e Department of Radiotherapy, UKSH Lübeck, Ratzeburger Allee 160, Lübeck 23538, Germany \\ ${ }^{\mathrm{f}}$ Institute for Radio-Oncology, Donauspital Vienna, Langobardenstrasse 122, Vienna A-1220, Austria
}

\section{A R T I C L E I N F O}

\section{Article history:}

Available online 2 February 2016

\section{Keywords:}

Medical physics

Medical physicist

Policy statement

National registration scheme

\begin{abstract}
A B S T R A C T
This EFOMP Policy Statement is an update of Policy Statement No. 6 first published in 1994. The present version takes into account the European Union Parliament and Council Directive 2013/55/EU that amends Directive 2005/36/EU on the recognition of professional qualifications and the European Union Council Directive 2013/59/EURATOM laying down the basic safety standards for protection against the dangers arising from exposure to ionising radiation. The European Commission Radiation Protection Report No. 174, Guidelines on Medical Physics Expert and the EFOMP Policy Statement No. 12.1, Recommendations on Medical Physics Education and Training in Europe 2014, are also taken into consideration.

The EFOMP National Member Organisations are encouraged to update their Medical Physics registration schemes where these exist or to develop registration schemes taking into account the present version of this EFOMP Policy Statement (Policy Statement No. 6.1"Recommended Guidelines on National Registration Schemes for Medical Physicists").
\end{abstract}

(c) 2016 Published by Elsevier Ltd on behalf of Associazione Italiana di Fisica Medica.

\section{Introduction}

One of the principal objectives of EFOMP is to harmonise and promote the best practice of medical physics in Europe. In pursuing this objective, one of the long term aims of EFOMP is to achieve uniformity in the application of high standards of education, training and performance of medical physicists in the countries of its National Member Organisations (NMOs). This aim can be achieved through the recognition of the Medical Physics profession by the European Union, by meeting the requirements of the European Union Directive 2005/36/EC on the recognition of professional qualifications as amended by Directive 2013/55/EU of the European Parliament and of the council of 20 November 2013 [1].

Disclaimer Note: EFOMP Policy Statement No.6.1 has been approved by EFOMP Council in Marburg (Germany) on 12 September 2015. Hence this paper has not been subjected to standard peer review, being an official policy statement of the European Federation of Organisations for Medical Physics.

* Corresponding author. Biomedical Research Foundation, P.O. Box 24039, Nicosia 1700, Cyprus. Tel.: +357 22322 278; fax: +357 22325415.

E-mail address: c4stelios@gmail.com (S. Christofides)
Chapter IIIA of Directive 2013/55/EU offers recognition on the basis of common training principles (Chapter IIIA of Directive 2013/55/EU is reproduced in Appendix A, for easy reference).

The new European Union Council Directive 2013/59/EURATOM laying down the basic safety standards for protection against the dangers arising from exposure to ionising radiation (EU BSS) [2], gives the definition of the Medical Physics Expert (MPE), the roles, responsibilities and the need for the continuous education and training, as well as the need for the MPE to be recognised by the relevant competent authorities of the European Union Member States.

The European Commission Radiation Protection Report No. 174 (RP 174) [3] offers European guidelines on the Medical Physics Expert in line with the EU BSS and presents the qualification framework of the MPE in terms of the European Qualification Framework for Lifelong Learning recommendations [4].

The independence of universities in providing education and training courses is acknowledged. Due to this independence it is hard to find Master's courses from two universities that cover all the required knowledge, skills and competence (KSC) that a medical physicist with a Master's degree must have when first employed. That is why it is recommended by RP 174 that such a person must work under supervision for at least two years and at the same time 
must undergo the recommended clinical training. It is stressed that additional education is required during the clinical training to bridge the gaps between the education attained during the Master's course and that which is required according to the recommendations in RP 174. Therefore there is no European wide recognition at the educational stage due to the Bologna declaration. Recognition is possible after the clinical training stage, if at least one third of the European Union Member States agree to a "common training framework" and a "common training test" as specified in the European Union Directive 2013/55/EU in its Chapter IIIA.

As many terms are used worldwide to define the professional stage of a medical physicist (qualified, clinically qualified, specialist, expert and consultant) it is to be understood that in the European context, the title "Medical Physicist (MP)" is only to be used for individuals that have the training and education in compliance with the requirements in RP 174 (i.e. they are qualified to Master's degree level and have at least 2 years clinical training in their specialty of medical physics). See Appendix B for an explanation of the terms used.

A registration scheme, which is set up by a national law or by a national medical physics organisation on a voluntary basis, should register individuals that have achieved the level of MP. Based on RP 174 , it is wise that a registration scheme also has a register (or list) for recently qualified medical physicists (at the Master's or equivalent level) and has a procedure (or system) in place, by which it assesses their qualifications and identifies their gaps in knowledge, skills and competence. A procedure (or system) should also be in place that assists these medical physicists to enrol in a residency programme or undergo apprenticeship for the required period of time to fulfil the requirements to be registered as an MP in their particular field of interest, based on their identified gaps.

A national registration scheme should also have a continuous professional development programme to assure that the registered MPs maintain their competence to remain on the register.

Furthermore, it is advisable that a national registration scheme has a procedure (or system) in place to attest to the advanced knowledge, skills and competence that an individual must have in order to be recognised by the relevant national competent authority as an MPE in a particular specialty of medical physics. Only the relevant national competent authority can then have a register for the recognised medical physics experts. Such a registration scheme should also have a procedure for continuous professional development to ensure that the registered individual MPEs maintain their competence to remain on this register.

In some Member States the above two registration schemes can be one and the same, if allowed by the national law, or through an agreement between the national medical physics organisation and the relevant national competent authority.

This policy statement is based on the requirements and recommendations of the above European Union documents. The EFOMP National Member Organisations (NMOs) are encouraged to bring in line their voluntary national registrations schemes, where they already exist or to set up their registration scheme, in line with these recommendations. Where the registration scheme is run by an independent organisation that was set up by law, relevant amendments to the law should be encouraged.

\section{Aim and objectives}

The two principal objectives of a Registration Scheme for medical physicists are:

(1) To protect the health, wellbeing and safety of patients, staff and members of the public by ensuring medical physicists are competent to act or give advice in their field of expertise.
(2) To ensure that the medical physicist continues to advance the physical sciences in their application to the prevention, diagnosis, therapy and control of illness, disease and disability through the requirement to participate in a continuous professional development (CPD) scheme in order to maintain their registration.

The aim of this policy statement is to encourage the EFOMP NMOs, where a statutory registration scheme does not exist, to:

(a) Update their medical physicist's registration scheme in line with the recommendations of this Policy Statement, where they already exist.

(b) To set up a medical physicist's registration scheme in line with the recommendations of this Policy Statement where they do not exist.

(c) To have their medical physicist's registration scheme recognised by EFOMP.

The registration schemes can be either statutory or indicative (i.e. voluntary) but must satisfy the general criteria laid down by EFOMP if they are to be recognised by EFOMP and eventually by the European Commission, thus ensuring the free movement of medical physicists across the European Union.

Where a Member State has a statutory registration scheme for medical physicists and/or Medical Physics Experts (i.e. operated through a regulatory authority), EFOMP will normally automatically recognise such schemes.

\section{Benefits of a recognised registration scheme}

There are benefits of a recognised Registration Scheme for all parties:

(1) For the patients, the major benefit is the protection afforded by their care being provided by medical physicists whose ability has been independently assessed as being at an appropriate level.

(2) For the medical physicist, freedom of movement is facilitated since EFOMP can confirm that the necessary training and practical experience have been acquired.

(3) For the NMOs and National Societies, knowledge of the number of registered medical physicists will help in discussions on training requirements and staffing levels in their own countries.

(4) For EFOMP, the overall picture will be of value in discussions with the European Commission, the IAEA, the WHO and other international organisations on the harmonisation of standards at an appropriate level. EFOMP will also be in a position to press for formal regulated recognition of the profession.

(5) For the European Commission, it is a means for facilitating free movement of medical physicists across the European Union.

\section{Recommendations}

According to the Qualifications Framework of the Medical Physics Expert in Europe [3] it is possible to recognise three stages in the professional development of a medical physicist. A national registration scheme should include procedures (or systems) that cover all the three stages of the Medical Physics profession:

(A) Educational stage (when someone achieves their Master's in Medical Physics or equivalent following a BSc in physics or equivalent) 
(B) Clinically Competent stage (when one has achieved the required KSCs to work alone and has the corresponding recognition)

(C) Medical Physics Expert stage (when the MP achieves the required KSCs to EQF Level 8 and hence be recognised by the relevant national competent authority as a Medical Physics Expert).

All these stages need to be accommodated since Medical Physicists at each stage need, in most Member States, to be employed after or concurrently with the Master's stage in order to progress through Lifelong Learning to the other two stages. If these Medical Physicists are not registered or recognised, then they will not easily be employed. Each stage needs to be harmonised and accepted by all Member States in order for the profession to be recognised by the European Union and to be able to move freely and be employed across the European Union.

It is also important that any registration scheme should, to start with, recognise the persons that have been working as medical physicists for some years before the registration scheme is set up, irrespective if they fulfil the requirements of the registration scheme or not. For the clinically competent stage, usually a period of five years minimum prior to the start of the registration scheme is universally acceptable (the so called "Grandfathering clause"). Procedures (or systems) should be put in place to assist these medical physicists to achieve the requirements of the registration scheme though Lifelong Learning if they want to progress to the higher levels of the medical physics profession.

In order to reach harmonisation in the recognition of the Medical Physics profession and to allow free mobility of the Medical Physicists between the EU Member States, it is recommended that a formal mechanism for recognising an individual's status as a Medical Physicist should be put in place in each EU member State by appointing, through a legal instrument, a Registration Council or Equivalent, specifically for the registration of Medical Physicists. The registration of the Medical Physicists should be based on the recommendations specified in RP 174 [3].

The criteria that EFOMP will look at before accepting a national Registration Scheme are:

(1) A clear statement of the aims of the scheme including the levels of recognition.

(2) A properly constituted Registration Council or equivalent. Smaller organisations to which this task has been delegated to, can consider having an EFOMP representative on their Council or equivalent, at least for the first few years, to ensure harmonisation of standards.

(3) A clear statement of criteria of scientific knowledge and practical competencies for inclusion on the Register. It is recommended that these are in line with the learning outcomes prescribed in RP174 at the appropriate level in order to meet the requirements of paragraph 2 of article 49a of Directive 2013/55/EU [1] (see Appendix A).

(4) Evidence that there is a training programme that is consistent with the RP 174 and the EFOMP policy statement on education and training.

(5) A mechanism for identifying expert areas of registrants (e.g. Radiotherapy, Diagnostic and Interventional Radiology, Nuclear Medicine, etc.).

(6) A regular renewal mechanism with a requirement for evidence of continuing activity in relevant areas (enrolment in a CPD scheme, see EFOMP policy statement No. 10 [5]).

(7) Agreed rules of Professional Conduct, in line with the EFOMP Policy statement No. 11 [6].

(8) Definition of Professional Misconduct and procedures for disciplinary action. Agreement in principle to investigate reported cases of professional misconduct. Details of the procedures adopted need to be provided.

EFOMP does not wish to be over-prescriptive in deciding the nature of Registration Schemes. However, it recognises that further guidance need to be added in order to reach a standardised format. Therefore, the chairperson and the members of the EFOMP Professional Matters Committee are ready to assist the EFOMP NMOs to set up their registration schemes.

\section{Application procedure}

NMOs and National Societies that have formulated registration schemes which they believe to be in accordance with the above guidelines are invited to submit details to the EFOMP Professional Matters Committee Chairperson, preferably in electronic format and translated into English, at: professionalmatterscommittee@efomp.org.

Approved registration schemes will be issued with a certificate of approval that will be valid for five years. One year before the expiry date, the national registration scheme must submit a renewal request. If, at any time during the approved period, there are changes to the approved registration scheme, these must be notified to the Professional Matters Committee to be examined to make sure that they still fulfil the requirements of this Policy Statement.

A list of Registration Schemes that have been approved by EFOMP will be published from time to time on the EFOMP website.

EFOMP will give the fullest possible support to promoting recognised schemes and to any individual registered on such a scheme.

\section{Procedure to be followed after EFOMP approval}

According to paragraph 3 of article 49a of Chapter IIIA of Directive 2013/55/EU (see the Appendix A), EFOMP intends to submit to the European Commission suggestions for a common training framework which meets the conditions laid down in paragraph 2 of article 49a, when at least a third of the Member States of the European Union have registration schemes with education and training components in line with the learning outcomes of RP 174.

Furthermore, EFOMP is in the process of setting up an examination board in accordance with article $49 \mathrm{~b}$ of Chapter IIIA of Directive 2013/55/EU (see the Appendix A). EFOMP intends to submit to the European Commission suggestions for a common training test which meets the conditions laid down in paragraph 2 of article 49b, when at least a third of the Member States of the European Union agree to accept the common training test of the EFOMP Examination Board.

It is therefore important that the registration schemes of the EFOMP NMOs be as harmonised as closely as possible.

Once the above have been implemented and approved according to the conditions of Chapter IIIA of Directive 2013/55/EU, the Medical Physics Profession can be recognised by the European Union with all the benefits of free movement across the European Union.

\section{Summary}

The Guidelines present the conditions of the national registration schemes for Medical Physicists required for EFOMP approval. Adherence to these conditions by at least one third of the EFOMP NMOs that are also European Union Member States will allow EFOMP to submit to the European Commission suggestions for a common training framework and a common training test in order to achieve recognition of the Medical Physics Profession by the European Union.

The EFOMP National Member Organisations are encouraged to update their Medical Physics registration schemes where these exist 
or develop registration schemes for Medical Physicists taking into account the present Policy Statement.

\section{Acknowledgements}

The authors acknowledge the help of the EFOMP Officers in compiling this Policy Statement.

\section{Appendix A Extract from Directive 2013/55/EU of the European Parliament and of the Council of 20 November 2013 amending Directive 2005/36/EC on the recognition of professional qualifications and Regulation (EU) No 1024/2012 on administrative cooperation through the Internal Market Information System ('the MI Regulation')}

\section{Chapter IIIA}

\section{Automatic recognition on the basis of common training principles Article 49a \\ Common training framework}

(1) For the purpose of this Article, 'common training framework' means a common set of minimum knowledge, skills and competences necessary for the pursuit of a specific profession. A common training framework shall not replace national training programmes unless a Member State decides otherwise under national law. For the purpose of access to and pursuit of a profession in Member States which regulate that profession, a Member State shall give evidence of professional qualifications acquired on the basis of such a framework the same effect in its territory as the evidence of formal qualifications which it itself issues, on condition that such framework fulfils the conditions laid down in paragraph 2.

(2) A common training framework shall comply with the following conditions:

(a) The common training framework enables more professionals to move across Member States;

(b) The profession to which the common training framework applies is regulated, or the education and training leading to the profession is regulated in at least one third of the Member States;

(c) The common set of knowledge, skills and competences combines the knowledge, skills and competences required in the systems of education and training applicable in at least one third of the Member States; it shall be irrelevant whether the knowledge, skills and competences have been acquired as part of a general training course at a university or higher education institution or as part of a vocational training course;

(d) The common training framework shall be based on levels of the EQF, as defined in Annex II of the Recommendation of the European Parliament and of the Council of 23 April 2008 on the establishment of the European Qualifications Framework for lifelong learning $\left({ }^{1}\right)$;

(e) The profession concerned is neither covered by another common training framework nor subject to automatic recognition under Chapter III of Title III;

(f) The common training framework has been prepared following a transparent due process, including the relevant stakeholders from Member States where the profession is not regulated; (g) The common training framework permits nationals from any Member State to be eligible for acquiring the professional qualification under such framework without first being required to be a member of any professional organisation or to be registered with such organisation.

(3) Representative professional organisations at Union level, as well as national professional organisations or competent authorities from at least one third of the Member States, may submit to the Commission suggestions for common training frameworks which meet the conditions laid down in paragraph 2.

(4) The Commission shall be empowered to adopt delegated acts in accordance with Article 57c to establish a common training framework for a given profession based on the conditions laid down in paragraph 2 of this Article.

(5) A Member State shall be exempted from the obligation of introducing the common training framework referred to in paragraph 4 on its territory and from the obligation of granting automatic recognition to the professional qualifications acquired under that common training framework if one of the following conditions is fulfilled:

(a) There are no education or training institutions available in its territory to offer such training for the profession concerned;

(b) The introduction of the common training framework would adversely affect the organisation of its system of education and professional training;

(c) There are substantial differences between the common training framework and the training required in its territory, which entail serious risks for public policy, public security, public health or for the safety of the service recipients or the protection of the environment.

(6) Member States shall, within six months of the entry into force of the delegated act referred to in paragraph 4, notify to the Commission and to the other Member States:

(a) The national qualifications, and where applicable the national professional titles, that comply with the common training framework; or

(b) Any use of the exemption referred to in paragraph 5, along with a justification of which conditions under that paragraph were fulfilled. The Commission may, within three months, request further clarification if it considers that a Member State has provided no or insufficient justification that one of these conditions has been fulfilled. The Member State shall reply within three months of any such request.

The Commission may adopt an implementing act to list the national professional qualifications and national professional titles benefiting from automatic recognition under the common training framework adopted in accordance with paragraph 4.

(7) This Article also applies to specialties of a profession, provided such specialties concern professional activities the access to and the pursuit of which are regulated in Member States, where the profession is already subject to automatic recognition under Chapter III of Title III, but not the specialty concerned.

Article 49b

Common training tests

(1) For the purpose of this Article, a 'common training test' means a standardised aptitude test available across participating Member States and reserved to holders of a particular 
professional qualification. Passing such a test in a Member State shall entitle the holder of a particular professional qualification to pursue the profession in any host Member State concerned under the same conditions as the holders of professional qualifications acquired in that Member State.

(2) The common training test shall comply with the following conditions:

(a) The common training test enables more professionals to move across Member States;

(b) The profession to which the common training test applies is regulated, or the education and training leading to the profession concerned is regulated in at least one third of the Member States;

(c) The common training test has been prepared following a transparent due process, including the relevant stakeholders from Member States where the profession is not regulated;

(d) The common training test permits nationals from any Member State to participate in such a test and in the practical organisation of such tests in Member States without first being required to be a member of any professional organisation or to be registered with such organisation.

(3) Representative professional organisations at Union level, as well as national professional organisations or competent authorities from at least one third of the Member States, may submit to the Commission suggestions for common training tests which meet the conditions laid down in paragraph 2.

(4) The Commission shall be empowered to adopt delegated acts in accordance with Article 57c to establish the contents of a common training test, and the conditions required for taking and passing the test.

(5) A Member State shall be exempted from the obligation of organising the common training test referred to in paragraph 4 on its territory and from the obligation of granting automatic recognition to professionals who have passed the common training test if one of the following conditions is fulfilled:

(a) The profession concerned is not regulated on its territory;

(b) The contents of the common training test will not sufficiently mitigate serious risks for public health or the safety of the service recipients, which are relevant on its territory;

(c) The contents of the common training test would render access to the profession significantly less attractive compared to national requirements.

(6) Member States shall, within six months of the entry into force of the delegated act referred to in paragraph 4 , notify to the Commission and to the other Member States:

(a) The available capacity for organising such tests; or

(b) Any use of the exemption referred to in paragraph 5, along with the justification of which conditions under that paragraph were fulfilled. The Commission may, within three months, request further clarification, if it considers that a Member State has provided no or insufficient justification that one of these conditions has been fulfilled. The Member State shall reply within three months of any such request.

The Commission may adopt an implementing act to list the Member States in which the common training tests adopted in accordance with paragraph 4 are to be organised, the frequency during a calendar year and other arrangements necessary for organising common training tests across Member State.
Appendix B Explanation of terms used in defining the level of medical physicists

The International Atomic Energy Agency, through its publications, recommends two levels of Medical Physicists:

- Qualified Medical Physicist (QMP). When someone achieves their Master's in Medical Physics or equivalent

- Clinically Qualified Medical Physicists (CQMP). When one has achieved the required KSCs to work alone and has the corresponding recognition

The second level is implied in the International Basic Safety Standards [1] in the definition of Medical Physicist:

"Medical physicist: A health professional with specialist education and training in the concepts and techniques of applying physics in medicine and competent to practise independently in one or more of the subfields (specialties) of medical physics.

I Competence of persons is normally assessed by the State by having a formal mechanism for registration, accreditation or certification of medical physicists in the various specialties (e.g. diagnostic radiology, radiation therapy, nuclear medicine). States that have yet to develop such a mechanism would need to assess the education, training and competence of any individual proposed by the licensee to act as a medical physicist and to decide, on the basis of either international accreditation standards or standards of a State where such an accreditation system exists, whether such an individual could undertake the functions of a medical physicist, within the required specialty".

Additionally in the European Union the Medical Physics Expert is defined as:

"medical physics expert, means an individual or, if provided for in national legislation, a group of individuals, having the knowledge, training and experience to act or give advice on matters relating to radiation physics applied to medical exposure, whose competence in this respect is recognised by the competent authority"

Internationally a number of terms are used to signify different levels of the Medical Physics Profession. These are not clearly defined and depending on the context used they could mean the same level. Same examples are given below to illustrate the confusion that currently exists.

For example the term "Medical Physics Expert" as defined by the European Union Directive 2013/59/Euratom, is not equivalent to "Medical Physics Specialist". This is evident from the definition of the two words (from the Oxford dictionary):

Expert: is a person who is very knowledgeable about or skilful in a particular area

Specialist: is a person who concentrates primarily on a particular subject or activity; a person highly skilled in a specific and restricted field

For example one may be a Medical Physics Expert in Nuclear Medicine and/or a Medical Physics Specialist in PET/CT.

The term "Expert", if referred to an individual, is closer related to the term "Consultant" (defined by the Oxford dictionary as a person who provides expert advice professionally).

Considering and analysing the definition of "Medical Physics Expert" as given by Directive 2013/59/Euratom, it should be understood that this definition is still very confusing. It may be considered that the term "Medical Physics Expert" is not a person, but a function that needs to be fulfilled by someone (an individual) 
or a medical physics service within an organisation (a group of individuals. See RP 174 page 11 footnote and page 27 first paragraph). This function is to reassure the relevant competent authorities that the licensee, fulfils his/her legal obligations. The total competence of this function must be recognised by the relevant competent authority.

RP 174 specifies the KSCs that "an individual" must have to be recognised by the relevant competent authority as a "Medical Physics Expert". A relevant national competent authority may transpose the above directive differently, i.e. recognise individuals and or group of individuals to fulfil this function depending on the facility to be licensed to use ionising radiation.

Therefore the individual experts are not specialists as they need to be competent in a particular field of medical physics, or part of it, as recognised by the relevant competent authority. They may be considered as consultants in a particular field of Medical Physics.

For uniformity, therefore, in the present EFOMP Policy Statement, it is to be understood that in the European context the title "Medical Physicist (MP)" is only be used for individuals that have the training and education in compliance with the requirements in RP 174 (i.e. they are qualified to Master's degree level and have at least 2 years clinical training in their specialty of medical physics). NMOs are encouraged to use this understanding in order to achieve uniformity in the terms used internationally and thus avoid the confusion that currently exists.

\section{References}

[1] Parliament and council directive 2013/55/EU. Off J Eur Union 2013;L 354

[2] Council directive 2013/59/EURATOM. Off J Eur Union 2014:L 013.

[3] Guidelines on medical physics expert. European Commission. Radiat Prot $2014 ; 174$.

[4] Parliament and council recommendation 2008/C 111/01. Off J Eur Union 2008;C111.

[5] EFOMP policy statement No.10, "Recommended guidelines on national schemes for continuing professional development of medical physicists". Phys Med 2001;XVII:97-101. Available also from the EFOMP Website <http://www.efomp .org/index.php/component/content/article/87-professionalissues/106-policy -statements>; [accessed 28.10.14].

[6] EFOMP policy statement No.11, "Guidelines on professional conduct and procedures to be implemented in the event of alleged misconduct". Available also from the EFOMP Website. Phys Med 2003;XIX:227-9. <http://www.efomp .org/index.php/component/content/article/87-professionalissues/106-policy -statements>; [accessed 28.10.14]. 